\title{
Size-exclusion chromatography (SEC) of branched polymers and polysaccharides
}

\author{
Marianne Gaborieau • Patrice Castignolles
}

Received: 30 June 2010 /Revised: 6 September 2010 / Accepted: 13 September 2010 /Published online: 22 October 2010

(C) The Author(s) 2010. This article is published with open access at Springerlink.com

\begin{abstract}
Branched polymers are among the most important polymers, ranging from polyolefins to polysaccharides. Branching plays a key role in the chain dynamics. It is thus very important for application properties such as mechanical and adhesive properties and digestibility. It also plays a key role in viscous properties, and thus in the mechanism of the separation of these polymers in sizeexclusion chromatography (SEC). Critically reviewing the literature, particularly on SEC of polyolefins, polyacrylates and starch, we discuss common pitfalls but also highlight some unexplored possibilities to characterize branched polymers. The presence of a few long-chain branches has been shown to lead to a poor separation in SEC, as evidenced by multiple-detection SEC or multidimensional liquid chromatography. The local dispersity can be large in that case, and the accuracy of molecular weight determination achieved by current methods is poor, although hydrodynamic volume distributions offer alternatives. In contrast, highly branched polymers do not suffer from this extensive incomplete separation in terms of molecular weight.
\end{abstract}

Published in the special issue Separation Science of Macromolecules with Guest Editor André Striegel.

P. Castignolles $(\bowtie)$

School of Natural Sciences, Australian Centre for Research on Separation Science (ACROSS), University of Western Sydney, Locked Bag 1797,

Penrith South DC, NSW 1797, Australia

e-mail: p.castignolles@uws.edu.au

\section{Gaborieau}

Nanoscale Organisation and Dynamics Group, School of Biomedical and Health Sciences, University of Western Sydney, Locked Bag 1797 ,

Penrith South DC, NSW 1797, Australia
Keywords Size-exclusion chromatography $\cdot$ Gel permeation chromatography $\cdot$ Branching $\cdot$ Polyolefins . Polyacrylates $\cdot$ Starch

\section{Introduction}

Branched polymers are present in our everyday life as the main component of plastic bags (polyethylene) and our main source of calories (starch). Mechanical properties and digestibility are the most important application properties in these two examples. In both cases, and many others, the branching significantly influences the application properties [1].

Size-exclusion chromatography (SEC) has a quasimonopoly on the molecular characterization of polymers in general, and this is also true for branched polymers. The method appeared in the late $1950 \mathrm{~s}$ and was named gel permeation chromatography (GPC) [2] or gel filtration chromatography (GFC) [3]. The group of Benoit revealed that GPC or GFC separates by hydrodynamic volume [46]. The separation is thus based on size exclusion, which is why IUPAC recommends using the term SEC instead of GPC. Further breakthroughs in SEC have been the development of online detectors, especially light-scattering detectors [7-9] and viscometers [10, 11], and more recently mass spectrometers [12]. Although the presence of branches significantly changes the hydrodynamic volume, the possible consequences of branching for the separation of branched polymers by SEC are generally ignored in the literature. The aim of this review is to discuss the impact of branching in SEC separation by critically reviewing findings scattered across 30 years from a number of different countries and to deal with samples with radically different applications. This will allow us to discuss the characterization of branched polymers from SEC data. The 
determination of molecular weight distributions can for example be plagued by very low accuracy in some cases, but not in others. Other tools, such as the hydrodynamic volume distribution, have important but unfulfilled potential that will also be discussed.

A large number of SEC features are relevant for branched polymers, but only the most relevant are discussed in this review. For a more comprehensive discussion of SEC, the reader is referred to recent literature [13-16]. SEC is not the only method used to characterize branched polymers. Most of our current knowledge of branched polymers actually derives from light scattering, and has been critically and comprehensively reviewed by Burchard [17]. However, light scattering requires large molecular weights and sizes (radius of gyration larger than $12 \mathrm{~nm}$ [18]). Current research thus mostly relies on the hyphenation of SEC or other separation methods with light scattering $[13,15]$. NMR can provide the average degree of branching per sample in a straightforward way $\left({ }^{1} \mathrm{H}\right.$ solution-state NMR of starch [19]) or in a less straightforward way $\left({ }^{13} \mathrm{C}\right.$ melt-state NMR of polyethylene [20] and polyacrylates [21]). Mass spectrometry can be complementary [22]: it does not separate isomers like those that occur due to branching, but it does allow the analysis of end groups and gives information on the mechanism of formation of branches in the case of the radical polymerization of acrylates [23]. Branching is important for rheological properties, and rheological studies can thus in turn characterize the average branching structure, as illustrated by the work on polyolefins [24, 25]. Finally, separation methods other than SEC can be used to characterize branched polymers. Field-flow fractionation (FFF) [26] will be briefly discussed for very large polymers, such as starch and polyolefins. HPLC methods other than SEC will also be discussed, and differences in separation mechanisms and the potential to separate according to the branching itself are emphasized. Capillary electrophoresis has been shown to be able to separate oligomers according to their structure (tacticity) [27], but the potential of the method for the separation of branched polymers is still under investigation.

There are two types of branches: short-chain and longchain ones (see Scheme 1). Short-chain branches are important for the crystallinity of material, as investigated in depth for polyethylene [28]. Short-chain branching also plays a key role in process engineering in the case of radical polymerization [29-31]. However, it has little influence on the SEC separation in some cases. Long-chain branching has a more profound and significant impact on SEC separation. The different definitions of short-chain and long-chain branching will be discussed in this review.

\section{Separation of branched polymers by SEC}

Important prerequisites for SEC: full dissolution, no adsorption onto stationary phase, no shear degradation, and an appropriate injection concentration

Dissolution is a necessary and often overlooked step for meaningful characterization in solution, particularly when using SEC, to ensure the whole sample is analyzed. This is especially true for branched polymers such as starch and polyolefins. Difficulty in obtaining a clear, transparent polymer solution (suspension) usually leads to the use of heat, sonication, microwave irradiation, acidic or basic conditions, or the addition of salt [28, 32-34]. These can lead to the hydrolysis of the polymer chain [35], and care needs be taken not to degrade polymers during dissolution and before analysis with SEC. Dissolution issues can be overcome through the use of different solvent systems, such as polar organic solvents with lithium salts for starch and cellulose [34, 36]. This approach takes advantage of different dissolution mechanisms, for example those for starch in aqueous versus organic media $[34,35]$. For starch in polar organic media, a visual test of dissolution was shown to be invalid: it is possible to obtain a clear and transparent starch suspension from which nothing precipitates upon centrifugation but within which starch is not completely dissolved [35]. We studied starch dissolution in DMSO with $\mathrm{LiBr}$, showing the limitations of light scattering and the successful use of ${ }^{1} \mathrm{H}$ solution-state NMR to quantify the kinetics [34] and the extent of dissolution [35]. Significant interactions of the polymer chains with the stationary phase can lead to a very complex and misleading
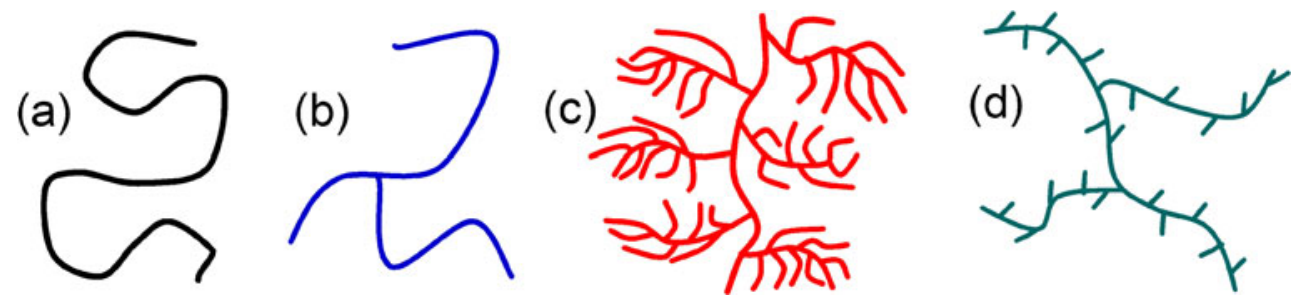

Scheme 1a-d Representation of a a linear polymer chain and various branched polymer structures with $\mathbf{b}$ long-chain branches (amylose-like), $\mathbf{c}$ short-chain branches (amylopectin-like), and d both short-chain and long-chain branches (polyacrylate- or polyethylene-like) 
separation: the lowest and highest molecular weights can co-elute and be separated only from the intermediate ones [37]; the reproducibility is low without the appropriate additive or appropriate stationary phase $[38,39]$, etc. Coelution can lead to an increase in the measured molecular weight with elution volume at higher elution volumes, which has been termed anomalous elution [40-43]. The presence of branches is not intrinsically a problem when separating with a size-exclusion mechanism (i.e., by hydrodynamic volume). This was demonstrated in the original work from Benoit with different polystyrene samples including combs and using tetrahydrofuran as eluent [4], or in the case of linear and branched polyethylenes using 1,2,4-trichlorobenzene as eluent [44]. Some end-groups can, however, favor interactions. In that case, the validity of universal calibration will be lost when the number of branches is increased, because the number of end-groups is increased. A neat example is hyperbranched polyesters: they follow universal calibration only after protecting their alcohol end-groups [45].

Some branched polymers have ultrahigh molecular weights, such as amylopectin in starch [46, 47], alternan [48], and some polyethylenes [49]. These can be degraded by shearing during the separation $[49,50]$. This has been reviewed and is qualitatively known. An alternative is to avoid high pressures by using separation methods without a stationary phase, such as field-flow fractionation [51, 52].

Very few standards are available to characterize branched polymers using conventional calibration SEC. Multiple-detection SEC is thus the tool of choice. However, the different sensitivities of the different detectors regularly prevent the determination of molecular weights across the whole chromatogram due to the low signal-to-noise ratio of the signal from one of the detectors [1]. This problem is most often encountered on the low molecular weight side when light scattering or viscometer signals have a lower sensitivity than concentration-sensitive detectors such as refractive-index detectors. Increasing molecular weight at high elution times can thus be an artefact that is related to the signal-to-noise ratio and data treatment, even when the signal-to-noise ratio looks high from a visual observation of the chromatograms [53]. The effect is observed even with the most modern and performant equipment, as seen for example in Figure 13b of a very recent multiple-detection SEC and FFF study of polyolefins [49]. This effect has also been called "anomalous elution" [40-43]: the controversy surrounding this term is discussed extensively on the third page of [54]. When a large and bimodal size distribution is measured, such as that of native starch, it may be impossible to obtain a reliable molecular weight, even using SEC MALLS. Removing the largest component (amylopectin or potentially aggregates) using ultracentrifugation allows a reliable molecular weight to be determined for the amylose component using SEC-MALLS [55]. The injection concentration thus needs to be high enough to obtain a sufficient signal over the relevant range of elution volumes for each detector. However, excessive injection concentrations may lead to shear degradation in the injector [50] and to extensive band broadening due to viscous fingering [56]. Viscous fingering occurs when a viscous liquid is pushed through a significantly less viscous one [57]. The critical injection concentration above which viscous fingering cannot be neglected has been determined empirically [58], and can be predicted from the following relation:

$[\eta] \times C \times 0.1 \times V_{i n j}<0.5$ to 1,

where $[\eta]$ is the intrinsic viscosity in $\mathrm{dL}^{-1}, C$ is the injection concentration in $\mathrm{g} \mathrm{L}^{-1}$, and $V_{\text {inj }}$ is the injection volume in $\mathrm{mL}$.

In the next sections, we assume that the polymer samples were fully dissolved, they do not significantly interact with the stationary phase, they do not significantly shear degrade, and that the injection concentration is optimal.

How does branching change SEC separation?

The main application of SEC is the determination of molecular weights. The use of apparent molecular weights (e.g., pullulan-equivalent or polystyrene-equivalent molecular weights) can induce nonsystematic and significant errors $[59,60]$. The occurrence of branching adds one more dimension to the complexity of the material, so the use of apparent molecular weights for branched polymers is not recommended. Multiple-detection SEC [14] allows true molecular weights to be evaluated by two independent methods: viscometry or light scattering. Viscometry enables the determination of molecular weights using a universal calibration curve. Light-scattering detectors yield absolute molecular weights (i.e., no need for a calibration curve) through low-angle laser light scattering, multi-angle laser light scattering, or triple detection [61]. Although a calibration curve is not used for light scattering, validating with a universal calibration (i.e., a size-exclusion separation) is strongly recommended in order to avoid co-elution. It is surprising that very few SEC characterizations have been validated by determining the molecular weight with two different methods. Pang and Rudin used this approach to confirm the reliability of their high-temperature SEC system for polyethylene [62]. Mueller's group used this method to validate the SEC separation of polyisocyanate and a highly branched polymethacrylate. The case of polyisocyanate demonstrates the importance of the polarity of the solvent [63]. The case of the highly branched polymethacrylate (a copolymer of methyl methacrylate 
(MMA) and 2-(2-methyl-1-triethylsiloxy-1-propenyloxy) ethyl methacrylate) [64] confirms the suitability of SEC, viscometry, universal calibration and light scattering for characterizing highly-branched polymers. We validated the separation of hydrophobic polyacrylates in tetrahydrofuran in the case of linear polyacrylates [54]. When produced by a radical process, polyacrylates are assumed to be longchain branched due to an intermolecular chain transfer-topolymer reaction. The occurrence, or not, of this transfer can be detected by an end-group analysis, as demonstrated by the group of Charleux in the case of the nitroxidemediated polymerization of acrylates studied by MALDITOF mass spectrometry [65]. This elegant approach is however limited to low molecular weights and processes leading to specific end-groups, and is not applicable in the case of the conventional radical polymerization used to produce many coatings and paints. Different types of branched polyacrylates have thus been characterized using multiple-detection SEC. However, in this case, viscometry and light scattering have been shown to lead to significantly different molecular weights. Viscometry consistently yields molecular weights that are slightly or much lower than those determined by light scattering $[21,54,66]$. Note that molecular weights can also be determined using universal calibration and the Mark-Houwink-Sakurada relation. However, this method is not universal, as the MarkHouwink-Sakurada relation is not universal; in particular, it is not valid in the case of statistically branched polymers $[21,67]$. Note also that triple detection combines light scattering and viscometry results in order to calculate the form factor through an iterative process. The theoretical background on the impact of branching on triple detection is limited. Experimentally, triple detection and LALLS yield the same molecular weights for branched polyacrylates [54], and triple detection has been used to characterize a number of branched polymers, such as regular stars [68].

SEC suffers from band broadening [69] and its inability to yield a complete separation such as that obtained with mass spectrometry [70]. For some branched polymers, branching causes the separation to be even less complete in terms of molecular weight. The reasons for this, limitations of it, and solutions to it are the main focus of the discussion which follows, especially in relation to the concept of local dispersity.

\section{Separation of branched polymers}

The difference in the molecular weights determined by different multiple-detection SEC methods was predicted by Hamielec [71-73]. The reason for it is that the hydrodynamic volume can significantly vary with the number, positions and lengths of the branches in polymer chains. Branching leads to a contraction of the polymer chain in terms of the hydrodynamic volume. Thus, when a linear and a branched polymer have the same hydrodynamic volume, the linear one has a lower molecular weight than the branched one. Since the separation is based on hydrodynamic volume in SEC, chains with different molecular weights can co-elute due to differences in their branching structures (see Fig. 1). The molecular weights determined by SEC at each elution volume are then only local average molecular weights. Hamielec predicted that light scattering would determine a local weight-average molecular weight, while viscometry would determine a local number-average molecular weight [16]. Light scattering leading to a weight-average molecular weight is expected from an early theory of the light scattering of polymers [74]. The case of viscometry is less trivial. Offline viscometry leads to the determination of a weight-average intrinsic viscosity and the viscosity-average molecular weight and not the number-average molecular weight. However, the use of online viscometry in SEC in conjunction with a universal calibration curve leads to the determination of the number-average molecular weight, as demonstrated by a complete derivation that takes band broadening into account [75]. This model is completely consistent with the experimental results: viscometry yields lower molecular weights than light scattering since numberaverage molecular weights are lower than weight-average ones.

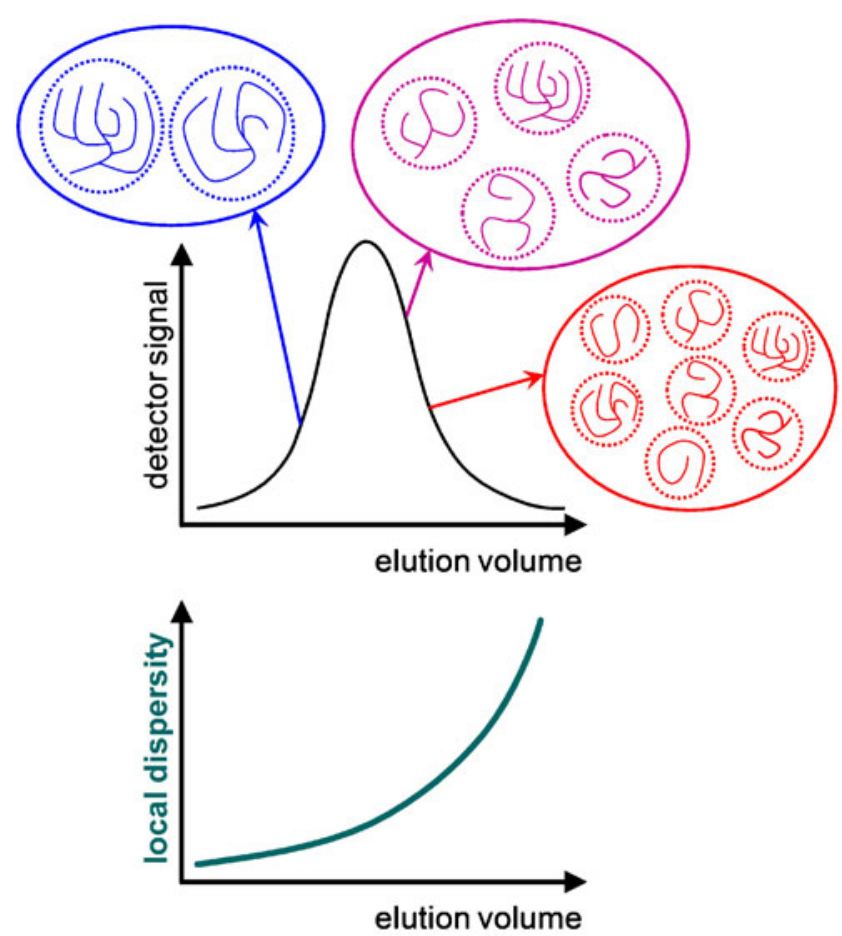

Fig. 1 Schematic representation of three populations of branched polymers within a SEC chromatogram and the corresponding local dispersity 
The effect of branching on SEC separation can be significant but it is variable. Multiple-detection SEC allows it to be quantified through the local dispersity [21, 54, 75]. Just like the definition of the "conventional" dispersity, the local dispersity is the ratio of the local weight-average molecular weight (from light scattering) to the local number-average molecular weight (from viscometry). Note that the local number-average molecular weight can also be determined from double detection when one of the endgroups can be selectively detected. An elegant and important example has been demonstrated by the group of Huber in the case of starch; this method takes advantage of selective labeling at the single reducing end of each molecule [76]. Local dispersity can also be determined using multi-dimensional liquid chromatography. In that case, SEC needs to be coupled to a method that separates according to a parameter related to the branching rather than the size [77-79]. This can be realized using interaction chromatography [77] or a molecular topology fractionation method, as done in the case of model star polymers [80]. Using molecular topology fractionation, the SEC co-elution of linear and star polymers differing by a factor of two in molecular weight has been observed. The effect is significant, even though it should be less important for well-defined branched polymers, as they possess only one branching topology and the branches have a narrow molecular weight distribution.

\section{Characterization of branched polymers using SEC}

Determination of the molecular weight distribution and hydrodynamic volume distribution

Local dispersity is significant when the branching creates heterogeneity; i.e., when there is no more a one-to-one relation between the hydrodynamic volume and the molecular weight. When all polymer chains are highly branched, the heterogeneity is not significant and the local dispersity is thus low [64]. The distribution of molecular weights can then be accurately determined using SEC. This may also be the case with regularly-branched polymers such as stars. Regular stars can be partially separated from their arms (before branching or after debranching) using SEC when the molecular weight of the arms is controlled during polymerization, for example using RAFT [68]. However, the situation is different for statistically branched polymers. Local dispersities of more than two have been measured with multiple-detection SEC for polyacrylates [54]. This means that the accuracy of the molecular weight distributions (and the $M_{\mathrm{n}}$ and $M_{\mathrm{w}}$ values for the whole sample) determined by SEC is low, even when using multiple detection. The error can be on the order of $100 \%$ for the molecular weight distribution [66]. A quantitative determination of molecular weights is necessary for example in the case of kinetic studies [30]. If statistical branching may be present, it is then important to determine the local dispersity in order to evaluate the (potentially large) inaccuracy. However, molecular weights are often used as relative values; i.e., for comparative studies. In that case, it is important to realize that the error in the molecular weight determination is not systematic: the local dispersity determined on polyacrylates strongly varies within one sample, in some cases from unity (high accuracy) to values above two (low accuracy). For comparative studies, we thus recommend that hydrodynamic volume distributions should be used instead. These are also very relevant to studies of polymer flow properties [81]. Hydrodynamic volume distributions are obtained via the same type of calculation as molecular weight distributions [75]. SEC hydrodynamic volume distributions, $w\left(\log V_{\mathrm{h}}\right)$, can be obtained from conventional single-detector SEC (typically using refractive index detection) together with either knowledge of the Mark-Houwink-Sakurada coefficients of the standards (and only the standards, not the sample) or the use of an online viscometer. The number hydrodynamic volume distribution, $N\left(V_{\mathrm{h}}\right)$, can be calculated from $w\left(\log V_{\mathrm{h}}\right)$ and the local number-average molecular weight, $M_{\mathrm{n}}\left(V_{\mathrm{h}}\right) . N\left(V_{\mathrm{h}}\right)$ can also be obtained directly from single-detection viscometry (Goldwasser method) [82]. The accuracy of the number hydrodynamic volume distribution is not lowered by the presence of branching. Hydrodynamic volume distributions have been used to perform comparative studies to investigate the mechanism of action of starch branching enzyme. A comparison of the hydrodynamic volume distributions of linear and branched glucans was performed [19]. The value of the local dispersity has never been measured for natural polymers, including for polysaccharides in which the presence of long-chain branches is strongly suspected, such as amylose of starch [83] or arabinoxylans (through ferulic acids) [84]. The $M_{\mathrm{w}}$ values of different starches obtained by offline light scattering and SEC-MALLS have been compared [85]. Starch dissolution was optimized in this work, and SEC exhibited quantitative starch recovery. No significant differences in $M_{\mathrm{w}}$ were observed for amylopectin, but a significant difference appeared and increased when the proportion of amylose in this starch increased. One possible explanation for this would be a local dispersity of $>1$ for the amylose fraction.

\section{Detection of long-chain branching}

The substantial impact of branching on the hydrodynamic volume allows its detection using SEC. Two main methods are available: comparison with a linear equivalent and local dispersity measurement. It is also possible to quantify 
branching from a logarithmic plot of the radius of gyration against the molecular weight [17]. However, strong nonlinearities are often observed experimentally [43], which are strongly linked to the sensitivity and anomalous elution controversy described in the previous section.

Branching can be detected by comparing the solution properties of the branched polymer and a linear equivalent [17]. This can be done using a number of methods, including SEC. All of these methods share one main limitation: the need for a linear equivalent of the same size. This is a tedious requirement to fulfill in the case of synthetic polymers such as polyethylene or starch, and is impossible for amylopectin, which is too large. Different variables can be used. One of the most popular is the MarkHouwink-Sakurada plot. Curvature is observed for polyolefins in this plot when branching is present $[28,44]$. This also underlines the invalidity of the Mark-HouwinkSakurada relation in the case of statistically branched polymers. Mark-Houwink-Sakurada parameters have also been shown to strongly depend on the branched structure in the case of branched polyacrylates [21,67]. This method allows the detection of a high level of branching, as in the case of the chain copolymerization of a monomer (such as methyl methacrylate) with a difunctional one, yielding highly branched polymers and clear differences in the MHS plots [86]. However, this method has been criticized for its low sensitivity, which is too low to detect long-chain branching in cases where the branching has already changed the rheological properties of the polymer [87-89].

When the detection of low levels of branching is required, the local dispersity can be measured for polyacrylates, as we recently demonstrated. Local dispersity is sensitive to the heterogeneity introduced by the branches, not to the amount of branching. Low local dispersities are thus expected (and observed) for linear polymers as well as highly branched or regularly branched ones. Polycondensation kinetics simulations also predict that $\mathrm{A}_{2}+\mathrm{A}_{3}$ polycondensation should lead to low local dispersity [90]; i.e., branched polymers which are homogeneous in terms of molecular weight and branching. In contrast, multipledetection SEC showed that large local dispersities are obtained for statistically branched polyacrylates. The heterogeneity is sensitive to very low levels of long-chain branching. Some of the highest local dispersities have been measured for polyacrylates obtained by controlled radical polymerization $[64,91]$ and at very low levels of longchain branching [54]. The nonlinearity of the effect of branching on SEC separation is a limitation when determining molecular weights, as it introduces a nonsystematic error. However, this nonlinearity is an advantage when the detection of low levels of long-chain branching is required, since it ensures highly sensitive detection. The detection limit depends on the solution properties and the molecular weight of the backbone and branches, but it is expected to be far lower than any other method. The two methodscomparison with a linear equivalent and measurement of local dispersity - are thus complementary.

The local dispersity concept can detect any heterogeneity, even if it does not arise from branching. Copolymer composition is another very important parameter [92], and composition gradients can be detected by measuring the local dispersity. Differences in the compositions of polymer blends are important, particularly for a number of industrial applications, and the local dispersity concept has already been applied to polymer blends with success [93]. In both cases, possible variations in the specific refractive index increment, $\mathrm{d} n / \mathrm{d} c$, need to be taken into account as an additional parameter.

\section{Quantification of long-chain branching}

Comparison with a linear equivalent should also enable the quantification as well as the detection of branching. The theory developed by Zimm [94, 95] is very popular and has been extensively and successfully tested in the case of regularly branched polymers [68]. However, this theory has a number of limitations when applied in SEC [96]. The theory assumes that the polymer chain is in a theta solvent, even though a good solvent is recommended for SEC. The theory also assumes that the local dispersity is close to 1 , while we have seen that it can significantly deviate from unity. The theory relates the radius of gyration to the degree of branching. It does not consider statistical branching with, for example, a distribution of molecular weights for the branches. The relation between the radius of gyration and the hydrodynamic volume or the intrinsic viscosity is complex in the case of branched polymers. The FloryFox coefficient does indeed change with branching [97]. SEC separation is related to hydrodynamic properties, and the most precise quantities determined are related to these hydrodynamic properties. The current theory is thus more of a fitting tool than a model for the quantification of branching in statistically branched polymers by SEC. Accurate quantification of branching may thus be possible only in the case of polyethylene, which has been extensively studied [17, 62].

Other liquid chromatography methods used to separate branched polymers

SEC is the most widely accessible method that is used to separate branched polymers, but its mechanism of separation is probably not the most appropriate. A number of publications investigate alternatives: liquid chromatography at the critical condition (LCCC), and different types of interaction chromatographies. When separation of linear 
polymers does not occur at the critical condition, some separation of the branched polymers can be achieved using LCCC [98]. The critical condition can be tedious to identify [99] (although it may be available from the literature), and the recovery is an important parameter that should not be overlooked [100]. Interaction chromatography is generally performed using a solvent gradient or a temperature gradient. A solvent gradient has recently been shown to successfully separate polyolefins, despite the high temperature and harsh solvents required [101]. Temperature gradient demonstrated a fast development [102].

A deeper understanding of the separation mechanism is necessary for HPLC methods to gain in characterizing power and popularity. Comparative studies of the different methods are highly valuable, as recently shown [77]. The dimensionality of a branched analyte is high, with varying molecular weights, branch lengths, branching topologies, branch point locations, end-groups, etc. The accurate and relevant characterization required is not possible using a single method. Multidimensional liquid chromatography is thus particularly appropriate for characterizing branched polymers $[78,79,103,104]$.

\section{Branched polymers}

To conclude this review, we discuss the SEC of branched polymers from a different point of view-the sample, for a few important examples: starch, polyethylene, polyacrylates, and poly(vinyl acetate).

Branching in polyethylene has been identified very early. Depending on the polymerization process, it exhibits both short- and long-chain branches $[44,105,106] .{ }^{13} \mathrm{C}$ NMR is the method of choice for quantifying the average degree of branching in polyethylene [28]. It was recently shown by Klimke et al. that the most sensitive measurements are performed in the melt, and a method was developed to estimate the experimental error in the measurement [20]. ${ }^{13} \mathrm{C}$ NMR probes the local environment, and can only differentiate branch lengths of up to 10 carbons based on high-resolution spectroscopy in solution [28], or up to 16 carbons based on the relaxation behavior in the melt [107]. The quantification of long-chain branching by SEC is not as accurate as NMR can be [62]; however, it can access a larger range of branch lengths and macromolecule sizes. It also allows changes in the branched structure to be monitored for different hydrodynamic volumes within a sample. It allows materials and polymerization processes to be compared [108, 109]. SEC and NMR are especially complementary in the case of polyethylene [28]. The local dispersity has been shown to be very close to unity for linear polyethylene by Pang and Rudin [62]. This confirms the reliability of their high-temperature SEC conditions. They also observed a local dispersity that was very close to unity for low-density polyethylene (LDPE), except for the largest molecules. Using the molecular weights determined by LALLS and viscometry in their Figure 3, the local dispersity can be estimated to increase up to 2 at the lowest elution volume before the cut-off indicated by Pang and Rudin. Multiple-detection SEC may thus allow the detection of long-chain branching in sparsely branched polyolefins using the SEC conditions from Pang and Rudin.

Polyacrylates are the main component of many paints and coatings in their hydrophobic form [poly(methyl acrylate), poly(butyl acrylate)s, poly(2-ethylhexyl acrylate), etc.]. They are the main components of superabsorbents in their hydrophilic form [or poly(acrylic acid)]. The presence of branches in radical polymerization processes has been detected using advanced ${ }^{13} \mathrm{C}$ NMR - extensively in the case of hydrophobic polyacrylates [21, 22, 110-113], and in a few instances in the case of hydrophilic polyacrylates [114, 115]. These branches mainly consist of short-chain branches. The presence of gels or microgels may prevent meaningful characterization, or at least the characterization of the whole sample, using SEC [112]. Long-chain branches have also recently been detected using multipledetection SEC [54].

Polyacrylates and polyethylene both possess short and long branches. It is important to note that the crossover between short- and long-chain branches has not been clearly defined and depends on the point of view. When considering the kinetics of radical polymerization, short- and long-chain branching usually refers to different types of transfer-topolymer reactions [29, 71]. Backbiting leads to short-chain branches of a defined length (typically two monomer units). Long-chain branches are attributed to other transfer-topolymer processes - intermolecular chain transfer to polymer and intramolecular transfer to polymer-but not backbiting. In that sense, long-chain branches can take any length between one and an infinite degree of polymerization. However, when some rheological properties such as melt properties are considered, short- and long-chain branches are distinguished in a different manner based on the critical degree of polymerization. Poly(vinyl acetate) obtained by radical polymerization also possesses some long-chain branches, as detected by SEC-LALLS [72] and SECMALLS [116, 117].

Starch is not only one of the most abundant polymers on earth, but also one of the most complex to characterize. Its two components are branched: amylose has a few longchain branches, while amylopectin is highly branched. The average degree of branching can easily be measured by ${ }^{1} \mathrm{H}$ NMR in solution [118, 119]. Dissolution is controversial: aqueous solutions are widely used but generally lead to incomplete dissolution and recovery as well as nonreproducible precipitation (known as retrogradation), although suitable conditions have been identified in some cases 
[120]. Dissolution in a polar organic solvent is also controversial. Dissolution and SEC in dimethyl sulfoxide (DMSO) have been used for 25 years [121], while dimethyl acetamide has also been tested with some success [122]. Wet DMSO (DMSO with 5-10\% water) has been shown to swell starch granules more rapidly than dry DMSO [123]. The dissolution itself may occur more rapidly in the absence of water [34]. There is some indication that universal calibration may be valid for the SEC of starch in aqueous eluents [124]. The very large size of amylopectin should prevent the analysis of native starch using SEC, and FFF is preferred by different groups [51, 52]. However, recent SEC work using fluorescent labeling and detection indicates that the molecular weight of amylopectin is orders of magnitude lower than commonly considered, and has led to the hypothesis that amylopectin is some kind of stable aggregate [76]. Despite the difficulties and controversies involved, knowledge of the branching structure of starch has been advanced based on the capacity of some enzymes to selectively and efficiently debranch starch. SEC can then be used to determine the molecular weight distribution of the branches [125], although capillary electrophoresis and ion chromatography may be more accurate [126]. However, chemical debranching processes have been criticized for their low reproducibilities and the potential for artefacts when tested on synthetic regular stars [68].

\section{Conclusion}

SEC is an even more powerful tool for characterizing polymers than usually stated in the literature. However, a monodimensional separation faces immediate limitations when analyzing a multidimensional sample. Branched polymers are characterized by the degree of branching, the branching topology, the distribution of the molecular weights of the branches, and the distribution of molecular weights of the polymer chains. This is why SEC, even using multiple detectors, yields the molecular weights of branched polymers with highly variable accuracy: typically high for highly or regularly branched polymers, but lower for statistically branched polymers. To characterize a branched polymer by SEC, one must first understand its separation. While a qualitative understanding is now available, and is summarized in this review, very little quantitative information is available. Multiple-detection SEC and the concept of local dispersity have important roles to play in the quantification of branching by SEC and the complete and accurate characterization of branched polymers.

The concept of local dispersity, discussed in this review in relation to the SEC of branched polymers, also applies to other polymers and methods. Linear copolymers can exhibit local dispersity due to compositional fluctuations (in the case of copolymers) [92], or other factors. Local dispersity can also play a role in other separation techniques where separation is based on size, such as field-flow fractionation or hydrodynamic chromatography.

Acknowledgements We are grateful to Prof. Walther Burchard (Freiburg), Prof. Manfred Schmidt, Dr. Karl Fischer (Mainz), and Dr. Yohann Guillaneuf (Marseilles) for discussions.

Open Access This article is distributed under the terms of the Creative Commons Attribution Noncommercial License which permits any noncommercial use, distribution, and reproduction in any medium, provided the original author(s) and source are credited.

\section{References}

1. Balke ST, Mourey TH, Lusignan CP (2006) Size exclusion chromatography of branched polyethylenes to predict rheological properties. Int J Polym Anal Char 11:21-34

2. Moore JC (1964) Gel permeation chromatography. I. New method for molecular weight distribution of high polymers. J Polym Sci Part A 2:835-843

3. Porath J, Flodin P (1959) Gel filtration-method for desalting and group separation. Nature 183:1657-1659

4. Benoit H, Grubisic Z, Rempp P, Decker D, Zilliox JG (1966) Etude par chromatographie en phase liquide de polystyrenes lineaires et ramifies de structures connues. J Chim Phys 63:1507-1514

5. Grubisic Z, Rempp P, Benoit H (1967) A universal calibration for gel permeation chromatography. J Polym Sci B 5:753

6. Grubisic Z, Rempp P, Benoit H (1996) A universal calibration for gel permeation chromatography. J Polym Sci B 34:1707-1713

7. Cantow HJ, Siefert E, Kuhn R (1966) Zur Registrierenden Ermittlung Der Molekulargewichtsverteilung Von Polymeren. Chem Ing Tech 38:1032-1038

8. Wyatt PJ (1993) Light-scattering and the absolute characterization of macromolecules. Anal Chim Acta 272:1-40

9. Jordan RC (1980) Size exclusion chromatography with low-angle laser-light scattering detection. J Liq Chromatogr 3:439-463

10. Haney MA (1985) The differential viscometer. 2. Online viscosity detector for size-exclusion chromatography. J Appl Polym Sci 30:3037-3049

11. Lecacheux D, Lesec J, Quivoron C (1982) High-temperature coupling of high-speed GPC with continuous viscometry. 1 . Long-chain branching in polyethylene. J Appl Polym Sci 27:4867-4877

12. Gruendling T, Guilhaus M, Barner-Kowollik C (2009) Fast and accurate determination of absolute individual molecular weight distributions from mixtures of polymers via size exclusion chromatography-electrospray ionization mass spectrometry. Macromolecules 42:6366-6374

13. Striegel AM, Kirkland JJ, Yau WW, Bly DD (2009) Modern size exclusion chromatography. Wiley, Hoboken

14. Striegel AM (2005) Multiple detection in size-exclusion chromatography of macromolecules. Anal Chem 77:104A-113A

15. Striegel AM (2008) Size-exclusion chromatography: smaller, faster, multi-detection, and multi-dimensions. Anal Bioanal Chem 390:303-305

16. Kostanski LK, Keller DM, Hamielec AE (2004) Size-exclusion chromatography - a review of calibration methodologies. J Biochem Biophys Meth 58:159-186 
17. Burchard W (1999) Solution properties of branched macromolecules. Adv Polym Sci 143:113-194

18. Jackson C, Chen YJ, Mays JW (1996) Size exclusion chromatography with multiple detectors: solution properties of linear chains of varying flexibility in tetrahydrofuran. J Appl Polym Sci 61:865-874

19. Hernández JM, Gaborieau M, Castignolles P, Gidley MJ, Myers AM, Gilbert RG (2008) Mechanistic investigation of a starch branching enzyme using hydrodynamic volume SEC analysis. Biomacromolecules 9:954-965

20. Klimke K, Parkinson M, Piel C, Kaminsky W, Spiess HW, Wilhelm M (2006) Optimisation and application of polyolefin branch quantification by melt-state C-13 NMR spectroscopy. Macromol Chem Phys 207:382-395

21. Castignolles P, Graf R, Parkinson M, Wilhelm M, Gaborieau M (2009) Detection and quantification of branching in polyacrylates by size-exclusion chromatography (SEC) and melt-state ${ }^{13} \mathrm{C}$ NMR spectroscopy. Polymer 50:2373-2383

22. Gaborieau M, Koo SPS, Castignolles P, Junkers T, BarnerKowollik C (2010) Reducing the degree of branching in polyacrylates via midchain radical patching: a quantitative melt-state NMR study. Macromolecules 43:5492-5495

23. Junkers T, Koo SPS, Davis TP, Stenzel MH, Barner-Kowollik C (2007) Mapping poly(butyl acrylate) product distributions by mass spectrometry in a wide temperature range: suppression of midchain radical side reactions. Macromolecules 40:8906-8912

24. Wood-Adams PM, Dealy JM (2000) Using rheological data to determine the branching level in metallocene polyethylenes. Macromolecules 33:7481-7488

25. Vittorias I, Parkinson M, Klimke K, Debbaut B, Wilhelm M (2007) Detection and quantification of industrial polyethylene branching topologies via Fourier-transform rheology. NMR and simulation using the pom-pom model. Rheol Acta 46:321-340

26. Messaud FA, Sanderson RD, Runyon JR, Otte T, Pasch H, Williams SKR (2009) An overview on field-flow fractionation techniques and their applications in the separation and characterization of polymers. Prog Polym Sci 34:351-368

27. Gaborieau M, Causon T, Guillaneuf Y, Hilder E, Castignolles $P$ (2010) Molecular weight and tacticty of oligoacrylates by capillary electrophoresis - mass spectrometry. Aust J Chem 63:1219-1226

28. Striegel AM, Krejsa MR (2000) Complementarity of universal calibration SEC and C-13 NMR in determining the branching state of polyethylene. J Polym Sci B 38:3120-3135

29. Junkers T, Barner-Kowollik C (2008) The role of mid-chain radicals in acrylate free radical polymerization: branching and scission. J Polym Sci A 46:7585-7605

30. Asua JM, Beuermann S, Buback M, Castignolles P, Charleux B, Gilbert RG, Hutchinson RA, Leiza JR, Nikitin AN, Vairon JP, van Herk AM (2004) Critically evaluated rate coefficients for free-radical polymerization. 5 Propagation rate coefficient for butyl acrylate. Macromol Chem Phys 205:2151-2160

31. Nikitin AN, Castignolles P, Charleux B, Vairon JP (2003) Determination of propagation rate coefficient of acrylates by pulsed-laser polymerization in the presence of intramolecular chain transfer to polymer. Macromol Rapid Commun 24:778-782

32. Bello-Perez LA, Roger P, Baud B, Colonna P (1998) Macromolecular features of starches determined by aqueous high-performance size exclusion chromatography. J Cereal Sci 27:267-278

33. Aberle T, Burchard W, Vorwerg W, Radosta S (1994) Conformational contributions of amylose and amylopectin to the structural properties of starches from various sources. Starch/ Stärke 46:329-335

34. Dona A, Yuen C-WW, Peate J, Gilbert RG, Castignolles P, Gaborieau M (2007) A new NMR method for directly monitoring and quantifying the dissolution kinetics of starch in DMSO. Carbohydr Res 342:2604-2610
35. Schmitz S, Dona AC, Castignolles P, Gilbert RG, Gaborieau M (2009) Assessment of the extent of starch dissolution in dimethyl sulfoxide by 1H NMR spectroscopy. Macromol Biosci 9:506-514

36. Striegel AM (2003) Advances in the understanding of the dissolution mechanism of cellulose in DMAc/LiCl. J Chil Chem Soc 48:73-77

37. Berek D (2004) Enthalpic partition-assisted size exclusion chromatography. I. Principle of method. Macromol Symp 216:145-163

38. Mourey TH, Bryan TG (2002) Size-exclusion chromatography in 1,1,1,3,3,3-hexafluoro-2-propanol. J Chromatogr A 964:169-178

39. Adler M, Pasch H, Meier C, Senger R, Koban HG, Augenstein M, Reinhold G (2004) Molar mass characterization of hydrophilic copolymers. 1 . Size exclusion chromatography of neutral and anionic (meth)acrylate copolymers. e-Polymers 55:1-16

40. Johann C, Kilz P (1991) Utilization of size-exclusion chromatography / multiangle laser light scattering for the analysis of structured polymers. J Appl Polym Sci Appl Polym Symp 48:111-122

41. Gerle M, Fischer K, Roos S, Mueller AHE, Schmidt M, Sheiko SS, Prokhorova S, Moeller M (1999) Main chain conformation and anomalous elution behavior of cylindrical brushes as revealed by GPC/MALLS, light scattering, and SFM. Macromolecules 32:2629-2637

42. Frater DJ, Mays JW, Jackson C (1997) Synthesis and dilute solution properties of divinylbenzene-linked polystyrene stars with mixed arm lengths: evidence for coupled stars. J Polym Sci B 1997:141-151

43. Podzimek S, Vlcek T, Johann C (2001) Characterization of branched polymers by size exclusion chromatography coupled with multiangle light scattering detector. I. Size exclusion chromatography elution behavior of branched polymers. J Appl Polym Sci 81:1588-1594

44. Wild L, Guliana R (1967) Gel permeation chromatography of polyethylene-effect of long-chain branching. J Polym Sci A 5:1087-1101

45. Garamszegi L, Nguyen TQ, Plummer CJG, Manson JAE (2003) Characterization of hyperbranched aliphatic polyesters and their trimethylsilylated derivatives by GPC-viscometry. J Liq Chromatogr RT 26:207-230

46. Radosta S, Haberer M, Vorwerg W (2001) Molecular characteristics of amylose and starch in dimethyl sulfoxide. Biomacromolecules 2:970-978

47. Tetchi FA, Rolland-Sabate A, Amani GN, Colonna P (2007) Molecular and physicochemical characterisation of starches from yam, cocoyam, cassava, sweet potato and ginger produced in the Ivory Coast. J Sci Food Agric 87:1906-1916

48. Striegel AM, Isenberg SL, Cote GL (2009) An SEC/MALS study of alternan degradation during size-exclusion chromatographic analysis. Anal Bioanal Chem 394:1887-1893

49. Otte T, Brull R, Macko T, Pasch H, Klein T (2010) Optimisation of ambient and high temperature asymmetric flow field-flow fractionation with dual/multi-angle light scattering and infrared/ refractive index detection. J Chromatogr A 1217:722-730

50. Barth HG, Carlin FJ (1984) A review of polymer shear degradation in size-exclusion chromatography. J Liq Chromatogr 7:1717-1738

51. Lee S, Nilsson PO, Nilsson GS, Wahlund KG (2003) Development of asymmetrical flow field-flow fractionation-multi angle laser light scattering analysis for molecular mass characterization of cationic potato amylopectin. J Chromatogr A 1011:111-123

52. Rolland-Sabate A, Colonna P, Mendez-Montealvo MG, Planchot V (2007) Branching features of amylopectins and glycogen determined by asymmetrical flow field flow fractionation coupled with multiangle laser light scattering. Biomacromolecules 8:2520-2532 
53. Tackx P, Bosscher F (1997) Systematic deviations due to random noise levels in size exclusion chromatography coupled with multi angle laser light scattering. Anal Commun 34:295-297

54. Gaborieau M, Nicolas J, Save M, Charleux B, Vairon J-P, Gilbert RG, Castignolles P (2008) Multiple-detection size-exclusion chromatography of complex branched polyacrylates. J Chromatogr A 1190:215-233

55. Roger P, Tran V, Lesec J, Colonna P (1996) Isolation and characterisation of single chain amylose. J Cereal Sci 24:247-262

56. Czok M, Katti AM, Guiochon G (1991) Effect of sample viscosity in high-performance size-exclusion chromatography and its control. J Chromatogr 550:705-719

57. Shalliker RA, Guiochon G (2010) Solvent viscosity mismatch between the solute plug and the mobile phase: considerations in the applications of two-dimensional HPLC. Analyst 135:222-229

58. Moore JC (1970) Overload effect in gel permeation chromatography. Sep Sci 5:723-730

59. Netopilik M, Kratochvil P (2003) Polystyrene-equivalent molecular weight versus true molecular weight in size-exclusion chromatography. Polymer 44:3431-3436

60. Guillaneuf Y, Castignolles P (2008) Using apparent molecular weight from SEC in controlled/living polymerization and kinetics of polymerization. J Polym Sci A 46:897-911

61. Poche DS, Brown RJ, Meiske L (2002) Flow-injection polymer analysis of ethylene propylene diene monomer elastomers. I. J Appl Polym Sci 85:2178-2189

62. Pang S, Rudin A (1993) Size-exclusion chromatographic assessment of long-chain branch frequency in polyethylenes. In: Provder T (ed) Chromatography of polymers - characterization by SEC and FFF. Am Chem Soc, Washington, pp 254-269

63. Hofe T (1997) Synthese und Charakterisierung von Polyisocyanaten durch GPC mit Hilfe von molmassensensitiven Detektoren. Chemie und Pharmazie. Johannes Gutenberg University, Mainz, PhD Thesis

64. Simon PFW, Mueller AHE, Pakula T (2001) Characterization of highly branched poly(methyl methacrylate) by solution viscosity and viscoelastic spectroscopy. Macromolecules 34:1677-1684

65. Farcet C, Belleney J, Charleux B, Pirri R (2002) Structural characterization of nitroxide-terminated poly( $n$-butyl acrylate) prepared in bulk and miniemulsion polymerizations. Macromolecules 35:4912-4918

66. Castignolles P (2009) Transfer to polymer and long-chain branching in PLP-SEC of acrylates. Macromol Rapid Commun 30:1995-2001

67. Couvreur L, Piteau G, Castignolles P, Tonge M, Coutin B, Charleux B, Vairon JP (2001) Pulsed-laser radical polymerization and propagation kinetic parameters of some alkyl acrylates. Macromol Symp 174:197-207

68. Boschmann D, Edam R, Schoenmakers PJ, Vana P (2008) Z-RAFT star polymerization of styrene: comprehensive characterization using size-exclusion chromatography. Polymer 49:5199-5208

69. Baumgarten JL, Busnel JP, Meira GR (2002) Band broadening in size exclusion chromatography of polymers. State of the art and some novel solutions. J Liq Chromatogr RT 25:1967-2001

70. Gruendling T, Guilhaus M, Barner-Kowollik C (2008) Quantitative LC-MS of polymers: determining accurate molecular weight distributions by combined size exclusion chromatography and electrospray mass spectrometry with maximum entropy data processing. Anal Chem 80:6915-6927

71. Hamielec A (1982) Characterization of complex polymer systems by size exclusion chromatography-homopolymers with long-chain branching and copolymers with composition drift. Pure Appl Chem 54:293-307

72. Hamielec AE, Ouano AC, Nebenzahl LL (1978) Characterization of branched polyvinyl acetate by GPC and low-angle laser-light scattering photometry. J Liq Chromatogr 1:527554

73. Hamielec AE, Ouano AC (1978) Generalized universal molecular-weight calibration parameter in GPC. J Liq Chromatogr 1:111-120

74. Flory PJ (1953) Determination of molecular weights. In: Principles of polymer chemistry. Cornell University Press, Ithaca, pp 266-316

75. Gaborieau M, Gilbert RG, Gray-Weale A, Hernandez JM, Castignolles P (2007) Theory of size exclusion chromatography (SEC) of complex branched polymers. Macromol Theory Simul 16:13-28

76. Praznik W, Huber A (2005) De facto molecular weight distributions of glucans by size-exclusion chromatography combined with mass/molar-detection of fluorescence labeled terminal hemiacetals. J Chromatogr B 824:295-307

77. Al Samman M, Radke W, Khalyavina A, Lederer A (2010) Retention behavior of linear, branched, and hyperbranched polyesters in interaction liquid chromatography. Macromolecules 43:3215-3220

78. Gerber J, Radke W (2005) Separation of linear and star-shaped polystyrenes by two-dimensional chromatography. e-Polymers 45:1-12

79. Gerber J, Radke W (2005) Topological separation of linear and star-shaped polystyrenes by off-line 2D chromatography. Stars having high molar mass arms and quantification of the star fraction. Polymer 46:9224-9229

80. Edam R, Meunier DM, Mes EPC, Van Damme FA, Schoenmakers PJ (2008) Branched-polymer separations using comprehensive two-dimensional molecular-topology fractionation $\times$ sizeexclusion chromatography. J Chromatogr A 1201:208-214

81. Ferry JD (1980) Viscoelastic properties of polymers. Wiley, New York

82. Castignolles P, Gaborieau M (2010) Viscosimetric detection in size-exclusion chromatography (SEC/GPC): the Goldwasser method and beyond. J Sep Sci 33, in press. doi:10.1002/ jssci.201000511

83. Takeda Y, Tomooka S, Hizukuri S (1993) Structures of branched and linear molecules of rice amylose. Carbohydr Res 246:267272

84. Dervilly G, Saulnier L, Roger P, Thibault JF (2000) Isolation of homogeneous fractions from wheat water-soluble arabinoxylans. Influence of the structure on their macromolecular characteristics. J Agric Food Chem 48:270-278

85. Han JA, Lim H, Lim ST (2005) Comparison between size exclusion chromatography and micro-batch analyses of corn starches in DMSO using light scattering detector. Starch/Stärke 57:262-267

86. Saunders G, Cormack PAG, Graham S, Sherrington DC (2005) Use of rapid triple detection size exclusion chromatography to evaluate the evolution of molar mass and branching architecture during free radical branching copolymerization of methyl methacrylate and ethylene glycol dimethacrylate. Macromolecules 38:6418-6422

87. Piel C, Stadler FJ, Kaschta J, Rulhoff S, Munstedt H, Kaminsky W (2006) Structure-property relationships of linear and long-chain branched metallocene high-density polyethylenes and SEC-MALLS. Macromol Chem Phys 207:26-38

88. Vega JF, Fernandez M, Santamaria A, Munoz-Escalona A, Lafuente P (1999) Rheological criteria to characterize metallocene catalyzed polyethylenes. Macromol Chem Phys 200:2257-2268

89. Janzen J, Colby RH (1999) Diagnosing long-chain branching in polyethylenes. J Mol Struct 486:569-584 
90. Jackson C (1994) Computer-simulation study of multidetector size-exclusion chromatography of branched molecular-mass distributions. J Chromatogr A 662:1-12

91. Charleux B, Nicolas J (2007) Water-soluble SG1-based alkoxyamines: a breakthrough in controlled/living freeradical polymerization in aqueous dispersed media. Polymer 48:5813-5833

92. Ahmad IAH, Striegel AM (2010) Determining the absolute, chemical-heterogeneity-corrected molar mass averages, distribution, and solution conformation of random copolymers. Anal Bioanal Chem 396:1589-1598

93. Balke ST, Mourey TH (2001) Local polydispersity detection in size exclusion chromatography: method assessment. J Appl Polym Sci 81:370-383

94. Zimm BH, Stockmayer WH (1949) The dimensions of chain molecules containing branches and rings. J Chem Phys 17:13011314

95. Zimm BH, Kilb RW (1959) Dynamics of branched polymer molecules in dilute solution. J Polym Sci 37:19-42

96. Radke W, Muller AHE (2005) Synthesis and characterization of comb-shaped polymers by SEC with on-line light scattering and viscometry detection. Macromolecules 38:3949-3960

97. Farmer BS, Terao K, Mays JW (2006) Characterization of model branched polymers by multi-detector SEC in good and theta solvents. Int J Polym Anal Char 11:3-19

98. Im K, Park H-W, Kim Y, Ahn S, Chang T, Lee K, Lee H-J, Ziebarth J, Wang Y (2008) Retention behavior of star-shaped polystyrene near the chromatographic critical condition. Macromolecules 41:3375-3383

99. Favier A, Petit C, Beaudoin E, Bertin D (2009) Liquid chromatography at the critical adsorption point (LC-CAP) of high molecular weight polystyrene: pushing back the limits of reduced sample recovery. e-Polymers 9:1-15

100. Beaudoin E, Favier A, Galindo C, Lapp A, Petit C, Gigmes D, Marque S, Bertin D (2008) Reduced sample recovery in liquid chromatography at critical adsorption point of high molar mass polystyrene. Eur Polym J 44:514-522

101. Macko T, Pasch H (2009) Separation of linear polyethylene from isotactic, atactic, and syndlotactic polypropylene by hightemperature adsorption liquid chromatography. Macromolecules 42:6063-6067

102. Chang $\mathrm{T}$ (2005) Polymer characterization by interaction chromatography. J Polym Sci B 43:1591-1607

103. Im K, Kim Y, Chang T, Lee K, Choi N (2006) Separation of branched polystyrene by comprehensive two-dimensional liquid chromatography. J Chromatogr A 1103:235-242

104. Im K, Park H-w, Lee S, Chang T (2009) Two-dimensional liquid chromatography analysis of synthetic polymers using fast size exclusion chromatography at high column temperature. J Chromatogr A 1216:4606-4610

105. Billmeyer FW (1953) The molecular structure of polyethylene. 3. Determination of long chain branching. J Am Chem Soc 75:6118-6122

106. Roedel MJ (1953) The molecular structure of polyethylene.1. Chain branching in polyethylene during polymerization. J Am Chem Soc 75:6110-6112

107. Parkinson M, Klimke K, Spiess HW, Wilhelm M (2007) Effect of branch length on C-13 NMR relaxation properties in molten poly[ethyleneco-alpha-olefin)] model systems. Macromol Chem Phys 208:2128-2133

108. Tackx P, Tacx J (1998) Chain architecture of LDPE as a function of molar mass using size exclusion chromatography and multi-angle laser light scattering (SEC-MALLS). Polymer 39:3109-3113
109. Beer F, Capaccio G, Rose LJ (2001) High molecular weight tail and long-chain branching in low-density polyethylenes. J Appl Polym Sci 80:2815-2822

110. Ahmad NM, Heatley F, Lovell PA (1998) Chain transfer to polymer in free-radical solution polymerization of $n$-butyl acrylate studied by NMR spectroscopy. Macromolecules 31:2822-2827

111. Heatley F, Lovell PA, Yamashita T (2001) Chain transfer to polymer in free-radical solution polymerization of 2-ethylhexyl acrylate studied by NMR spectroscopy. Macromolecules 34:7636-7641

112. Plessis C, Arzamendi G, Leiza JR, Schoonbrood HAS, Charmot D, Asua JM (2000) Seeded semibatch emulsion polymerization of $n$-butyl acrylate. Kinetics and structural properties. Macromolecules 33:5041-5047

113. Plessis C, Arzamendi G, Alberdi JM, Agnely M, Leiza JR, Asua JM (2001) Intramolecular chain transfer to polymer in the emulsion polymerization of 2-ethylhexyl acrylate. Macromolecules 34:6138-6143

114. Llauro MF, Loiseau J, Boisson F, Delolme F, Ladaviere C, Claverie J (2004) Unexpected end-groups of poly(acrylic acid) prepared by RAFT polymerization. J Polym Sci A 42:54395462

115. Couvreur L (2003) Polymérisation et copolymérisation radicalaires de l'acide acrylique contrôlées par le nitroxyde SG1. Laboratoire de Chimie des Polymères, Université Pierre et Marie Curie, Paris, $\mathrm{PhD}$ Thesis

116. Grcev S, Schoenmakers P, Iedema P (2004) Determination of molecular weight and size distribution and branching characteristics of PVAc by means of size exclusion chromatography/ multi-angle laser light scattering (SEC/MALLS). Polymer 45:39-48

117. Baudry R, Sherrington DC (2006) Facile synthesis of branched poly(vinyl alcohol)s. Macromolecules 39:5230-5237

118. Gidley MJ (1985) Quantification of the structural features of starch polysaccharides by NMR spectroscopy. Carbohydr Res 139:85-93

119. Gaborieau M, DeBruyn H, Mange S, Castignolles P, Brockmeyer A, Gilbert RG (2009) Synthesis and characterization of synthetic polymer colloids colloidally stabilized by cationized oligosaccharides. J Polym Sci A 47:1836-1852

120. Rolland-Sabate A, Mendez-Montealvo MG, Colonna P, Planchot V (2008) Online determination of structural properties and observation of deviations from power law behavior. Biomacromolecules 9:1719-1730

121. Kobayashi S, Schwartz SJ, Lineback DR (1985) Rapid analysis of starch, amylose and amylopectin by high-performance sizeexclusion chromatography. J Chromatogr 319:205-214

122. Striegel AM, Timpa JD (1995) Molecular characterization of polysaccharides dissolved in $\mathrm{Me}_{2} \mathrm{NAc}-\mathrm{LiCl}$ by gel-permeation chromatography. Carbohydr Res 267:271-290

123. Mukerjea R, Robyt JF (2006) Controlled peeling of the surfaces of starch granules by gelatinization in aqueous dimethyl sulfoxide at selected temperatures. Carbohydr Res 341:757-765

124. Kuge T, Kobayashi K, Tanahashi H, Igushi T, Kitamura S (1984) Gel-permeation chromatography of polysaccharides - universal calibration curve. Agric Biol Chem 48:2375-2376

125. Sargeant JG (1982) Determination of amylose - amylopectin ratios of starches. Starch/Stärke 34:89-92

126. Morell MK, Samuel MS, O'Shea MG (1998) Analysis of starch structure using fluorophore-assisted carbohydrate electrophoresis. Electrophoresis 19:2603-2611 